\title{
Milton Friedman y la contrarrevolución keynesiana
}

\author{
Milton Friedman and the Keynesian \\ counter-revolution
}

Luis Armando Blanco* Julián Libreros

* Doctor en Ciencias Sociales del Colegio de México. Profesor Titular de la Facultad de Finanzas, Gobierno y Relaciones Internacionales de la Universidad Externado de Colombia, Bogotá, Colombia [luis.blanco@uexternado.edu.co].

** Magíster en Economía con énfasis en Teoría y Política Económica. Profesor asociado del Programa de Economía de la Universidad Jorge Tadeo Lozano, Bogotá, Colombia [julian. libreros@utadeo.edu.co].

Artículo recibido el 13 de marzo de 2019.

Aceptado el 15 de agosto de 2019.

Para citar este artículo:

Blanco, L. A. y Libreros, J. (2019). Milton Friedman y la contrarrevolución keynesiana. ODEON, 17, 7-43.

DOI: https://doi.org/10.18601/17941113.n17.02 


\section{Resumen}

La revolución contra la teoría cuantitativa la hizo Keynes en la década de los treinta dentro de la economía oficial. La contrarrevolución keynesiana la realizó Milton Friedman en la década de los setenta, también dentro del sistema teórico dominante y se conoció con los nombres de Escuela de Chicago, monetarismo o neoliberalismo, términos que nunca le gustaron al propio Friedman.

En el artículo se analizan algunos aspectos fundamentales de este gran cisma intelectual en la economía, en torno a la economía monetarista, la crítica a la curva de Phillips, la política monetaria y su explicación sobre los determinantes de las crisis económicas, especialmente el Gran Crac de 1929, para contrastarlo con la crisis de 2008.

Palabras clave: Crisis económicas; curva de Phillips; Friedman; Keynes; monetarismo; política monetaria; reglas monetarias; tasa natural de desempleo.

Clasificación JEL: B22, E00, E50, G01.

\section{Abstract}

The revolution against quantitative theory was made by Keynes in the 1930s within the official economy. The Keynesian counterrevolution was carried out by Milton Friedman in the seventies, also within the dominant theoretical system and was known as the Chicago School or Monetarism or Neoliberalism, terms that Friedman himself never liked.

In the article we analyze some fundamental aspects of this great intellectual schism in the economy, around the monetarist economy, the criticism of the Phillips curve, the monetary policy and its explanation on the determinants of the economic crises, especially the Great Crash of the 29 to contrast it with the 2008 crises.

Key words: Economic crises; Friedman; Keynes; monetarism; monetary policy; monetary rules; natural unemployment rate; Phillips Curve.

JEL classification: B22, E00, E50, G01.

\section{Introducción}

Milton Friedman (1912-2006) es quizás, junto con Keynes, el economista más brillante e influyente del siglo Xx, ganador del Premio Nobel de Economía en 1976 y responsable intelectual de la contrarrevolución keynesiana que sentó las bases del orden macroeconómico monetarista entre 1980 y 2008. 
En la década de los setenta, sus investigaciones obtuvieron el mayor reconocimiento con el Premio Nobel en Ciencias Económicas otorgado en 1976, por sus contribuciones al "análisis del consumo, historia y teoría monetaria, y por su demostración de la complejidad de la política de estabilización" (NobelPrize. Org, 2018). Al año siguiente se retiró de la Universidad de Chicago, pero a lo largo de su vida permaneció estrechamente ligado a la academia ${ }^{1}$ lo cual dejó claramente explicado en la siguiente frase: "Para que la sociedad sea a la vez humana y dé oportunidad a sus grandes logros, es necesario que una pequeña minoría de personas quienes no tienen objetivos materialistas, tengan el mayor grado de libertad" (Ip y Whitehouse, 2006).

Alguna vez, al ser interrogado sobre la importancia del Premio Nobel, Friedman decía que si bien era muy gratificante, su verdadera recompensa no provenía en sí del veredicto emitido por el Comité del Nobel, sino de lo que en verdad importa a un científico: "el efecto en el largo plazo de su trabajo sobre su ciencia" (Friedman, 1994, p. 173).

En la década de los ochenta mantuvo su producción de libros y artículos. En 1982, con Schwartz, culminó el trabajo que había iniciado con su Historia monetaria y, con el patrocinio del National Bureau of Economic Research (NBER), publicó Tendencias monetarias en los Estados Unidos y el Reino Unido: sus relaciones con el ingreso, precios y tasas de interés, 1967-1975, que sería la contraparte econométrica de la narrativa desarrollada en su Historia moneta$r i a^{2}$. Para la década de los noventa resaltan sus obras Economía monetarista (1991), Las paradojas del dinero: episodios en historia monetaria (1992) y sus memorias Two Lucky People (1998), escritas en coautoría con su esposa. Summers (2006) resumió su influencia de la siguiente manera: "nunca ocupó un cargo electo, pero ha tenido más influencia en la política económica actual que cualquier otra figura moderna que la haya ejercido en el mundo".

1 En 1962, la Universidad de Chicago le otorgó Paul Snowden Russell el Distinguished Service Professor Emeritus of Economics, que ejerció entre 1962 y 1981.

2 Como Friedman no efectuó un análisis exclusivo de la historia monetaria de los Estados Unidos posterior a 1960, Nelson (2007) se hizo cargo de la tarea mediante un trabajo de archivo; revisó las observaciones y predicciones de Friedman para el periodo 1961-2006 y concluyó que las décadas de los sesenta y setenta revelaron la resistencia de los responsables de política para aceptar sus criterios sobre tasas de cambio, control de la inflación; mientras que las décadas posteriores reafirmaron su preferencia por M2 como la definición de dinero y la defensa de una regla de tasa de crecimiento fija de la oferta de dinero. 
En el artículo analizamos algunos aspectos fundamentales de este gran cisma intelectual en la economía, a partir de una revisión teórica de las ideas más relevantes en la historia del pensamiento económico de Milton Friedman en torno a la teoría de los precios-empleo-expectativas; la teoría y la política monetaria y su explicación sobre los determinantes de las crisis económicas, especialmente el Gran Crac de 1929, para contrastarlo con la crisis de 2008.

El artículo se divide en cinco secciones. La primera se ocupa de los aspectos biográficos más relevantes de Milton Friedman en torno a su vida académica y profesional, con énfasis en las obras que determinarían las principales controversias macroeconómicas de finales del siglo Xx. La segunda se centra en el análisis de las tesis fundamentales de la economía monetarista. La tercera trata de la crítica de Friedman a la curva de Phillips que se constituye en la artillería pesada con la cual intentó derrumbar el castillo keynesiano y erigir un orden monetarista basado en la hipótesis de la tasa natural de desempleo. La cuarta sección explica la política monetaria basada en reglas, contrastando la regla propuesta por Friedman frente a reglas alternativas como las de Taylor y la inflación objetivo. La última, consiste en las lecciones que deja la crisis financiera de 2008 con respecto a la evolución de la política monetaria basaba en reglas o activismo discrecional y las novedosas propuestas de limitar el uso del efectivo por parte de Rogoff.

\section{Economía monetarista}

La contrarrevolución keynesiana fue asociada a los escritos de Milton Friedman, aunque el término que se popularizó fue el acuñado por Brunner (1968a) como monetarismo ${ }^{3}$, nombre que si bien no le parecía muy atractivo al propio Friedman, lo utilizó en la década de los setenta para rescatar la teoría cuantitativa de Fisher y la defensa de la política monetaria para el logro de la estabilidad macroeconómica, condición sine qua non de la prosperidad.

La idea básica de la teoría cuantitativa es que hay una relación directa y causal entre la cantidad de dinero, por un lado, y los precios, por el otro. Esta

3 Hacia la década de los ochenta consideraba que el monetarismo era un nuevo término para una vieja generalización empírica conocida como la teoría cuantitativa del dinero y lo que no era monetarismo, lo explicaba por los asuntos sobre los que no tenía mucho que aportar como la política fiscal, la política gubernamental hacia la industria o la tasa de crecimiento de largo plazo de la economía (Friedman, 1982). 
poderosa idea -que es quizás de las viejas tesis de la economía- fue popularizada en los Estados Unidos por Irving Fisher, para Friedman el mejor economista de su país de todos los tiempos, con la famosa ecuación cuantitativa que expresa sencillamente que el dinero multiplicado por la velocidad del dinero es igual a los precios multiplicado por el volumen de las transacciones: $M V=P T$.

Hasta los años treinta, la ecuación de Fisher fue ampliamente aceptada y, en consecuencia, la política monetaria era el instrumento macroeconómico disponible para estabilizar la economía. La Gran Depresión destruyó esta credibilidad y comenzaron a ganar consenso las tesis keynesianas que aseveraban, no solo que la política monetaria era ineficaz en una situación de trampa de la liquidez, sino que la alternativa para recuperar y conducir la economía debía provenir de la política fiscal. La contrarrevolución monetaria que lideró Friedman reexaminó la cuestión y señaló que, al contrario, la Gran Depresión era un "testamento trágico acerca de la efectividad de la política monetaria, no una demostración de su impotencia" (Friedman, 2008, p. 17).

La opinión de Friedman sobre este asunto es ampliamente conocida. La realidad, según él, es que la Gran Depresión, como muchos otros periodos con tasas de desempleo graves, se produjo por los errores del Gobierno y no por una estabilidad inherente a la economía privada. La Gran Depresión de los Estados Unidos, lejos de ser un signo de inestabilidad inherente al mercado, fue un testimonio del daño que pueden causar las equivocaciones de sus individuos cuando disponen de inmensos poderes sobre el sistema monetario, como los que posee la Reserva Federal, que durante ese periodo contrajo el stock de dinero en dos tercios.

El monetarismo moderno, en el sentido estricto del término, surgió con la publicación de Friedman (1956) "The quantity theory of money: A restatement", cuyo objetivo era recuperar la vieja tradición de la teoría cuantitativa del dinero, desde sus primeras formulaciones en el siglo XVI. Si bien la idea más simple es que la cantidad de dinero es la variable que determina el nivel de precios y la renta nominal, el análisis de Friedman fue más allá de la ecuación de Fisher que centraba la demanda de dinero en las transacciones e incluyó como argumentos de la función de demanda de dinero a la riqueza, su tasa de rendimiento esperado y la proporción de capital humano en relación con la riqueza no humana.

Milton Friedman descubrió que este modelo hacía que la teoría de Keynes pudiera ser refutada a través de investigaciones empíricas basadas en series de tiempo. El modelo pronostica que debe haber una alta correlación entre los cambios en $V$ y las variaciones en $Y$, lo cual implica la ausencia de cualquier 
correlación entre $M$ y $V$. El trabajo empírico de Friedman encontró lo opuesto: que $M$ y $Y$ estaban invariable y altamente correlacionadas y que las variaciones en $V$, si las hubiera, se correlacionaban positivamente con $M$ y no de manera negativa. Además, en Friedman y Schwartz (1963), su historia monetaria de los Estados Unidos apoyó su noción de que los cambios en la oferta de dinero eran exógenos y, como se mencionó, atribuyó la Gran Depresión de 1929-1933 a las políticas deflacionistas de la Reserva Federal que forzaron una fuerte reducción de la base monetaria ${ }^{4}$.

Keynes no negó la ecuación cuantitativa de Irving Fisher. Dijo otra cosa. Dijo que, aunque por supuesto $M V=P T$, la velocidad, en vez de ser altamente estable es muy adaptable. En otras palabras, según dijo, la velocidad va donde la lleva el viento. Se mueve en una u otra dirección respondiendo a los cambios en la cantidad de dinero o en los ingresos. Lo que importa, según Keynes no es la cantidad de dinero. Lo que importa es la parte del gasto total que es independiente de los ingresos corrientes que en la práctica se identifica en gran medida con las inversiones de las empresas y el gasto público. La gran recesión, según dijo, fue resultado de un colapso de la demanda de inversión lo que a su vez fue reflejo de las oportunidades productivas para invertir capital. (Friedman, 1992, p. 18)

Como suele ocurrir en la historia, en el momento en que las ideas de Keynes triunfaban en la política económica, comenzaban a perder influencia en las universidades más importantes de los Estados Unidos. Entre los factores que contribuyeron al ocaso del keynesianismo se pueden destacar, entre otros, que la inflación resultó ser el problema macroeconómico más importante de la Segunda Guerra Mundial, a tal punto que entre 1970 y 1980 la economía mundial experimentó una estanflación profunda. El ascenso de la nueva doctrina monetarista se fundamentó en extensas investigaciones empíricas sobre la relación entre la cantidad de dinero, los ingresos, precios y tasas de interés, y la revisión del episodio de la Gran Depresión en Friedman y Schwartz (1963).

Lo que la historia monetaria y las investigaciones empíricas demostraban, aparte de las malas decisiones de política de la Reserva Federal, era que los cambios en la velocidad del dinero tienden a reforzar los movimientos en la

4 En el verano de 1961, David Laidler, en su condición de estudiante de doctorado en la Universidad de Chicago, fue asistente de investigación del trabajo de Friedman y Schwartz (1963), y en la década de los noventa adhirió a la opinión de algunos economistas como Brunner (1968b), Humphrey (1971), Patinkin (1973), Sandilands (1990) y Steindl (1991) que acusaron a la corriente monetarista de omitir el trabajo pionero que realizó Currie (1931a, 1931b, 1934a, 1934b) al anticiparse en la interpretación monetaria de la Gran Depresión (Laidler, 1993). 
cantidad de dinero en vez de contrarrestarlos. En otras palabras, cuando la cantidad de dinero aumenta con rapidez en prácticamente cualquier país, la velocidad también lo hace.

Pero el golpe mortal para la ortodoxia keynesiana, por lo menos en los Estados Unidos, lo proporcionó Friedman con dos ideas sencillas: primera, al analizar los roles relativos de la política fiscal y la monetaria encontró que, en la práctica, la mayor parte del tiempo operan juntas; si el Gobierno imprime dinero para cubrir sus gastos, realmente estamos hablando de política monetaria. Segunda, la nueva interpretación de que las tasas de interés son un índice engañoso para orientar la política y que los banqueros centrales más bien deberían tener en cuenta la cantidad de dinero.

De las proposiciones que he presentado hasta aquí se deduce que la inflación es siempre y en todas partes un fenómeno monetario, en el sentido de que es y solo puede ser producida por un aumento más rápido de la cantidad de dinero que de la producción... El gasto gubernamental puede o no ser inflacionario. Claramente será inflacionario si se financia creando dinero, es decir, imprimiendo moneda o creando depósitos bancarios... Un aspecto importante de este mecanismo es que un cambio en el crecimiento monetario afecta las tasas de interés en una dirección en principio, pero más tarde en la dirección opuesta. Esta relación de doble filo, entre el dinero y las tasas de interés explica porque los monetaristas insisten en que la tasa de interés son un punto de referencia muy engañoso para la política monetaria. (Friedman, 1992, pp. 29-31).

La contraofensiva keynesiana tomó fuerza con el llamado de atención de Tobin (1981) acerca del "Monetarism Mark I", que se refería a si los cambios en los precios son la consecuencia de cambios previos en la cantidad de dinero en circulación o, por el contrario, los cambios en los ingresos y los precios son causados por otros factores que provocan, en consecuencia, cambios de ajuste en la oferta de dinero (Kaldor, 1987, p. 31).

El propósito de Tobin era responder a la contrarrevolución keynesiana integrando factores monetarios y actores reales en la economía. Es decir, intentando reconciliar el mundo prekeynesiano y el poskeynesiano.

La contraofensiva keynesiana comienza sustituyendo en la tradicional ecuación de Fisher: $M V=P T$, la $T$ de transacciones por la $Q$ (producción de Marshall). De tal forma que se obtiene la ecuación siguiente:

$$
P=\frac{M V}{Q}
$$


En donde:

$P$ : nivel de precio.

$M$ : cantidad de dinero.

$V$ : velocidad de circulación.

$Q$ : producción o ingreso en términos reales.

La "Reforma Pigou" a la teoría cuantitativa propone una ecuación alternativa

$$
P=(1+n) \frac{\partial L}{\partial Q} w
$$

En donde:

$L:$ trabajo.

$W$ : tasa de salario monetario por unidad de $L$.

$n$ : recíproco de la elasticidad de la demanda enfrentando al productor individual.

La diferencia entre ambas ecuaciones es que la segunda toma el nivel de salarios monetarios como determinado exógenamente y existen dos variables dependientes ( $P$ y $Q$ ) que se determinan de manera simultánea dependiendo del valor de $\mathrm{n}$.

Según Kaldor (1987), Keynes, quien fuera un verdadero seguidor de la teoría cuantitativa del dinero como la desarrolló Marshall, presentó otra solución en la que introdujo una ecuación que expresaba la preferencia por la liquidez, como se muestra a continuación:

$$
M=L(Y, r)
$$

en donde

$$
\begin{gathered}
Y=P Q \\
V(r)=\frac{Y}{M}
\end{gathered}
$$


En donde $V(r)$ es una forma alternativa de la preferencia por la liquidez y aparte de $P$ y $Q$, todas las variables son exógenas, incluyendo $M$. La consecuencia de esta interpretación de Keynes, generalmente aceptada, fue que todo el peso recayó en el cambio en la velocidad de circulación del dinero que se adapta por sí misma a los cambios en la demanda agregada.

Retomando a Kaldor, el rasgo extraordinario de todo lo escrito sobre el monetarismo en este siglo ha sido que el carácter exógeno de la oferta de dinero nunca fue cuestionado a pesar del hecho contundente de que la mayoría de los activos monetarios se originan en el crédito bancario, ya sea al sector público o al sector privado. Esto implica que buena parte de la discusión generada por el movimiento de Friedman pudo haberse evitado si Keynes (1936) hubiera reconocido explícitamente que la oferta monetaria $\mathrm{M}$ era también una variable endógena. Por consiguiente, la controversia se habría desarrollado de una forma más clara verificando empíricamente las dos posturas contrarias: la oferta de dinero exógena o endógena.

El debate se vio enriquecido con el trabajo empírico de Sims (1972), "Money, Income and Casuality", el cual sugería que los argumentos de Friedman eran correctos porque el stock de dinero podía considerarse en una regresión contra el ingreso como exógeno y, así, la ecuación resultante de la regresión caracterizaría la respuesta de la economía a cambios en la cantidad de dinero. Por tanto, dicha interpretación implicaba que solo una pequeña parte del cambio en el producto podía atribuirse a la oferta de dinero.

Fue Mehra (1978), quien aprendió sobre causalidad siendo estudiante de Sims, y revisó si las ecuaciones estaban bien especificadas; su sorpresa fue que, efectivamente, las ecuaciones - con el dinero como la variable dependiente-superaban las pruebas de exogeneidad para las tasas de interés y el producto. Estas aproximaciones condujeron a reflexionar a Sims (2011a, p. 11), quien declaró que "la única manera de conciliar esos resultados era juntar las variables en un modelo de ecuación múltiple para estudiar su dinámica".

En efecto, Sims (1980) emprendió dicho trabajo por medio de la estimación de un modelo vectorial autorregresivo (VAR) que incorporaba entre sus variables a las tasas de interés, la producción y el dinero. Su hallazgo fue revelador ya que en el periodo posterior a la Segunda Guerra Mundial, gran parte de la variación en el stock de dinero era predecible a partir de valores previos en las tasas de interés. Al mismo tiempo, los cambios en la tasa de interés en la posguerra eran predecibles y se basaban en los valores previos de la producción industrial. 
Entonces, si la tasa de interés era la variable relevante para los hacedores de política monetaria, el problema era que la política monetaria ahora resultaba predecible y sistemática, y el argumento de que tras la eliminación de su variación se reduciría el ciclo de los negocios ya no era confiable.

La proposición de que la inflación es un fenómeno monetario es el principio, aunque no el fin para entender por qué se produce dicho problema. Para su cabal comprensión es necesario investigar las razones que mueven en diferentes ritmos la oferta monetaria ampliada y la relación entre una alta inflación y un incremento del desempleo.

$\mathrm{Al}$ respecto, Friedman fue contundente cuando observó que los cambios en periodos breves del nivel general de precios pueden tener muchos orígenes, pero la inflación permanente por largo tiempo siempre y en todas partes es un fenómeno monetario resultado de una expansión más rápida en la cantidad de dinero que en la producción total. También fue claro en que terminar con la inflación requiere fundamentalmente el cierre del grifo monetario, de tal forma que no existe ningún problema técnico para terminarla, y que los verdaderos obstáculos provienen del proceso político.

La inflación elevada, sobre todo si es variable, tiende a hacer menos eficiente el sistema económico. Una función fundamental de un sistema de precios de mercado es transmitir de modo firme, eficaz y barato la información que los agentes económicos necesitan para tomar decisiones sobre cómo emplear los recursos. La información significativa es la que se refiere a los precios relativos de un producto con respecto a otro y de precios actuales en relación con precios futuros. Pero la información se transmite en forma de precios absolutos. El ruido que producen las transmisiones sobre inflación es que esta bloquea la transmisión sobre los precios relativos; para que no quede duda alguna cita al propio Keynes:

No hay medio más seguro y sutil de destruir la base actual de la sociedad que corromper la moneda. El proceso alista a todas las fuerzas ocultas de la ley económica del lado de la destrucción, y lo hace de un modo que no es capaz de diagnosticar ni un hombre entre un millón (John Maynard Keynes, 1920). (Friedman, 1984, p. 100)

Los efectos colaterales constituyen, según Friedman, el obstáculo político más importante para terminar con la inflación, que consiste en la falta de disposición o capacidad de los dirigentes políticos para persuadir al público de que acepte los efectos impopulares de una política ortodoxa. 
Estos efectos colaterales reflejan las distorsiones introducidas en los precios relativos por el cambio imprevisto en el nivel general de precios, pues los contratos se firman en términos de precios nominales bajo percepciones equivocadas acerca del curso probable de la inflación. La manera de reducir estas distorsiones es hacer contratos en términos reales, lo cual se puede lograr con el uso generalizado de las cláusulas de indexación. De ahí que Friedman abogó por el uso generalizado de dichas cláusulas de indexación en los contratos oficiales y propuso su uso generalizado de manera voluntaria en los contratos privados mediante un marco legal previamente establecido. "Aunque son muy útiles, las cláusulas indexatorias generalizadas no son una panacea. Es imposible indexar todos los contratos (basta pensar en el papel moneda) y es costoso indexar muchos" (Friedman, 1992, p. 46). Más adelante afirmó: "Repito, ninguno de estos arreglos deja de tener un costo. Sería mucho mejor si hubiera precios estables que los hiciera innecesarios. Pero a mí me parecen de un costo mucho menor que continuar por el camino de las aceleraciones periódicas de la inflación y que termine en una verdadera quiebra" (p. 54).

Para finalizar esta sección, pasamos al campo de la teoría monetaria internacional, donde la mayor aportación de Friedman fue, sin duda, su defensa de los tipos de cambio flexible. Como en otro de sus planteamientos, él estaba en contra de la opinión mayoritaria, pero el tiempo le dio la razón ya que consideraba que el peor mecanismo para conseguir el equilibrio en la balanza de pagos y el que más puede destruir la sociedad es el uso de las restricciones cuantitativas directas.

De los mecanismos consistentes con un mercado libre y con el libre comercio, solamente existían dos: el patrón oro internacional y los tipos de cambio libres determinados por medio de transacciones privadas sin intervención estatal. La solución del patrón oro la consideraba inviable e indeseable para el crecimiento económico y la estabilidad monetaria internacional; de tal forma que solo veía un mecanismo para equilibrar la balanza de pagos consistente con la libertad económica y similar a la norma monetaria que defendía, que eran los tipos de cambio fluctuantes.

Cuando proponemos un sistema nacional de precios libres no quiere ello decir que estemos a favor de un sistema en el que los precios fluctúen [...] hacia arriba y hacia abajo. Lo que queremos en un sistema en el que los precios fluctúen libremente pero que las fuerzas que los determinan sean lo suficientemente estables para que los precios se muevan dentro de límites moderados. El objetivo final es un mundo en el que los tipos de cambio, aunque con libertad para variar, tengan, de hecho, una gran estabilidad basada en políticas económicas y condiciones 
estables. La inestabilidad de los tipos de cambio es un síntoma de inestabilidad en la estructura económica básica. (Friedman, 2012, p. 76)

\section{Curva de Phillips: ¿desempleo frente a inflación?}

La revolución de Friedman brilló con su ataque a la curva de Phillips. La tesis fue contundente cuando afirmó que el debate sobre la curva de Phillips comenzó con la verdad en 1926, avanzó a través del error unos treinta años más tarde, y a esa altura retornó a 1926, es decir: unos cincuenta años para completar el circuito.

Según Friedman, el artículo de Fisher (1926) titulado "Statistical relation between unemployment and price changes", consideraba que la tasa de cambio de los precios es la variable independiente que pone al proceso en movimiento. Pero Phillips (1958) demostró lo contrario, él consideró que el nivel de empleo era la variable independiente que ponía en marcha el proceso y tomó la tasa de cambio de los salarios como la variable independiente.

El enfoque de Phillips (1958) difiere del de Fisher al tomar como variable independiente el nivel de empleo y la tasa de crecimiento de los salarios como la variable dependiente. Friedman opinaba que el análisis ofrecido por Phillips era muy rudimentario, pues estaba soportado en las condiciones estáticas de la oferta y la demanda.

Aunque Fisher se refería a variaciones en los precios y Phillips a variaciones en los salarios, ambos coincidían en que los salarios son uno de los elementos con mayor peso en el coste total, por lo que precios y salarios tienden a modificarse simultáneamente. No obstante, Friedman se opuso al análisis de Phillips porque implicaba que la oferta y la demanda de trabajo son funciones del salario nominal y no del real. Lo que esto implicaba es que existía una confusión entre salarios nominales y reales.

Friedman, en su exposición, sostuvo que el análisis de Phillips fue muy persuasivo pero totalmente falaz, porque jamás ningún teórico de la economía afirmó que el mercado laboral estuviera determinado por la tasa de salario nominal; confusión generada por el clima general engendrado por la revolución keynesiana. En la atmósfera keynesiana de aquella época era natural que Phillips diera por sentado que los salarios nominales reales se moverían juntos:

Lo que decía [Phillips] era un poco más complejo. Era que los cambios esperados en los salarios nominales eran iguales a los cambios esperados en los salarios reales. Había dos componentes 
del sistema keynesiano que eran esenciales para su construcción: Primero, la noción de que los precios son rígidos en el sentido de que la gente cuando planifica su comportamiento no deja lugar a la posibilidad de que pueda cambiar el nivel de precios, y por lo tanto considera un cambio en los salarios nominales o en los precios nominales como un cambio en los salarios reales y los precios reales; segundo, que los salarios reales expost, podrían ser alterados por una inflación no esperada. (Friedman, 2012, p. 87)

La interpretación de Friedman era aún más sofisticada, compleja y residía en que Phillips suponía que los cambios previstos en los salarios nominales eran iguales a los cambios previstos en los salarios reales. En dicha interpretación, dos argumentos cruciales son esgrimidos por Friedman:

... primero la idea de que los precios son rígidos en el sentido de que la gente, al planear su comportamiento, no dan entrada a la posibilidad de un cambio en el nivel de precios y, por consiguiente, consideran toda variación de los salarios nominales o de los precios nominales como una variación de los salarios o los precios reales; segundo, que los salarios reales podrían ser alterados ex post por una inflación imprevista. Ciertamente, toda la argumentación keynesiana afirmativa de la posibilidad de una política de pleno empleo partía de suponer que era posible conseguir que los trabajadores (al menos en los años 30, cuando Keynes escribió la Teoría General) aceptasen una reducción de los salarios reales provocada por una inflación, reducción que no habrían aceptado en la forma directa de una disminución en los salarios nominales. (Friedman, 1962, p. 269)

Para Friedman, había una diferencia crucial entre el análisis de Fisher y el de Phillips; entre la verdad de 1926 y el error en 1958 relacionado con la dirección de la causalidad:

Fisher consideró que la tasa de cambio de los precios es la variable independiente que pone al proceso en movimiento [...] Fisher estaba describiendo un proceso dinámico, nacido de las fluctuaciones de la tasa de gasto en torno de una tendencia o norma promedio. Dio gran importancia a la distinción entre precios altos y bajos, por un lado y a la subida y bajada de los precios por el otro. La distinción importante -y está claro que eso es lo que Fisher tenía en mente- es entre los cambios anticipados y los no anticipados. (Friedman, 1992, pp. 82 y 83)

El otro argumento se refería a que el ambiente intelectual de la época era importante en otro sentido: el ataque de los clásicos al sistema keynesiano conocido como la controversia de la ecuación faltante. Una razón fundamental de la rápida influencia del punto de vista de la curva de Phillips fue la creencia generalizada de que esta aportaba la ecuación faltante, que conectaba el sistema real con el sistema monetario, al determinar los precios en función de los salarios nominales 
y estos últimos con base en la tasa de desempleo. En opinión de Friedman, esta idea era falsa pues lo que faltaba para completar el sistema keynesiano era una ecuación que determinara el nivel de los precios de equilibrio.

Los fracasos empíricos de los trueques entre inflación y desempleo, y la estanflación en los años setenta y ochenta en la economía mundial, produjeron una reacción teórica general contra el sistema keynesiano, como también los intentos de reformular la curva de Phillips, al distinguir entre la forma de la curva en el corto y en el largo plazo. Si en el corto plazo se puede admitir una curva de Phillips con pendiente negativa, tal como se expone en la versión original, la curva de Phillips en el largo plazo debe asumir la forma clásica vertical, es decir, la oferta agregada se torna independiente del nivel general de precios, ya que los agentes económicos racionales y con expectativas racionales anticipan perfectamente los precios esperados (ver Anexo).

En mi alocución presidencial a la Asociación Norteamericana de Economía, argumenté que la curva de Phillips de largo plazo era vertical con base en la ausencia de toda ilusión monetaria de largo plazo [...] Esta hipótesis vino a ser llamada tasa natural debido al énfasis puesto en la tasa natural de desempleo. El término "la tasa natural" ha sido mal interpretado, no se refiere a un mínimo irreductible de desempleo. Más bien se refiere a esa tasa de empleo que es coherente con las condiciones reales existentes en el mercado laboral. (Friedman: 1992, pp. 93-94)

La experiencia de la estanflación y la controversia teórica fue formando un consenso de que la curva de Phillips era engañosa y exageraba mucho el trueque a corto plazo entre inflación y desempleo, pero muchos no estaban dispuestos a aceptar que el trueque de largo plazo era cero, es decir, la forma vertical de la curva de Phillips. La mayoría de las pruebas estadísticas incorporaron las expectativas adaptativas, donde la tasa esperada de inflación es un promedio exponencial ponderado de las tasas de inflación pasada. Las expectativas adaptativas tenían una gran acogida en la nueva econometría keynesiana y, al parecer, el mismo Friedman admite que le fue bien con su uso en muchos problemas.

Si bien Friedman fue prisionero, en cierto sentido, de las pruebas estadísticas basadas en las expectativas adaptativas, hay que subrayar que, en su trabajo seminal sobre la curva de Phillips, ya reseñaba la crítica fundamental que John Muth, Robert Lucas y Thomas Sargent denominaron como la "Hipótesis de las expectativas racionales". Este método supone que la gente forma sus expectativas basada en un modelo económico correcto; no es que acierte en cada caso individual ni en todo momento, sino que en un periodo prolongado en promedio acertará, mediante la incorporación de los errores en la formulación de sus 
expectativas; es decir, en el corto plazo existe error pero en el largo dicho error debe ser cero.

La curva de Phillips vertical a largo plazo también fue influenciada por los desarrollos de la teoría económica en las últimas décadas, especialmente el análisis de información imperfecta en el que fue pionero Joseph Stiglitz, y el papel del capital humano en la determinación de los contratos laborales realizado por Gary Becker. La integración de las expectativas racionales, el costo de adquisición de información y el papel del capital humano fueron sucesos que consolidaron el nuevo consenso en la teoría económica.

Para comprender este fenómeno, Friedman sugirió incluir en el análisis la interdependencia de la experiencia económica y los procesos políticos. Por eso considera que la tercera etapa, la curva de Phillips con pendiente positiva, sería influenciada por la aplicación del análisis económico al comportamiento político aprovechando los desarrollos de las escuelas de Chicago y de Virginia, con pioneros como Kenneth Arrow, Ducan Black, Anthony Downs, James Buchanan y Gordon Tullock.

El mismo Friedman amplió su argumento afirmando que la hipótesis de la tasa natural de desempleo no eliminaba la pendiente negativa de la curva de Phillips en el corto plazo; más bien, lo que sostuvo es que se trataba de un fenómeno temporal que desaparecería a medida que los agentes económicos adaptaran sus expectativas a la realidad. Es más, también sostuvo que la curva de Phillips podía adoptar una pendiente positiva correspondiente a periodos algo más largos, pero al igual que en el caso anterior, a medida que los agentes revisan sus expectativas, la curva de Phillips tiende a la tasa natural de desempleo. Este último caso excepcional fue el producto de su análisis sobre la economía latinoamericana que en los años ochenta presentó elevadas tasas de inflación crónica (Blanco, 1999).

Efectivamente, Friedman observó que la alta inflación de América Latina estaba acompañada de un mayor -y no un menor- desempleo en periodos de larga duración, es decir, una curva de Phillips de pendiente positiva, no negativa ni vertical, que constituía un desafío estadístico y teórico trascendental. Además, esta experiencia evidenció un fenómeno que, según Friedman, debía desaparecer a medida que los agentes económicos ajustaran, no solo sus expectativas, sino sus arreglos institucionales y políticos a una nueva realidad.

En el largo plazo, la curva de Phillips se ajustaba a la tasa natural de desempleo mediante las expectativas racionales y lo mismo debía suceder con la curva de pendiente positiva por medio de un proceso de ajuste como resultado 
de arreglos institucionales y políticos. Esto es fundamental en la teoría macroeconómica y ayuda a tener una visión más completa de la formulación de Friedman, pues normalmente solo se expone la primera parte de la solución.

La tendencia de la inflación alta a ser altamente variable, se ve reforzada por el efecto de la inflación sobre la cohesión política de un país en el que los arreglos institucionales y los contratos financieros han estado ajustados a un nivel normal de precios de largo plazo. Algunos grupos ganan y otros pierden. En los hechos el comportamiento "prudente" se convierte en aventurero y el comportamiento "aventurero" se vuelve prudente. La sociedad se polariza los grupos se enfrentan entre sí. Aumenta la intranquilidad política. La capacidad de cualquier gobierno se reduce al mismo tiempo que crece la presión por una acción decidida. (Friedman, 1992, p. 126)

Así, la década de los setenta en el mundo y de los ochenta en América Latina, dejaron una lección macroeconómica importante que condujo al mensaje influyente de Mundell: "La lección fue que la inflación, los déficit presupuestales, las deudas elevadas y el 'sector público amplio' son perjudiciales para el bienestar y que el costo de corregirlos es tan alto que ningún gobierno democrático quiere repetir la experiencia" (2003, p. 240).

\section{La política monetaria y la regla de Friedman}

En 1967, en su discurso ante la Asociación de Economistas de América (AEA), Friedman afirmó: "Estamos en peligro de asignar a la política monetaria un rol mayor del que puede cumplir, en peligro de que lleve a cabo tareas que no puede cumplir y, como resultado de esto en peligro de impedirle hacer el aporte que sí puede hacer" (1968, p. 12). La idea principal de este trabajo es que la política monetaria no debería utilizarse de forma discrecional para llevar a cabo políticas de "ajuste fino", sería preferible que la autoridad monetaria fijara una tasa de crecimiento estable para un agregado monetario determinado.

Antes de la Gran Depresión se creía que como en el caso de una cuerda, se podía tirar de ella para detener la inflación, pero no se le podía empujar para detener la recesión. La imagen en boga era que se podía llevar un caballo junto al agua, pero no se le podía forzar a beber. En medio de la Gran Depresión Keynes ofreció una explicación de la incapacidad de la política monetaria para vencer la depresión y una interpretación no monetaria de esta. Si la preferencia por la liquidez es absoluta en los periodos de crisis, los tipos de interés no pueden rebajarse con políticas monetarias y los tipos más bajos de interés no podrían resolver una crisis de demanda efectiva. Esta explicación se aceptó 
con avidez y la política monetaria quedó como dijo Friedman, “condenada dos veces" $(1968$, p. 2$)$.

El crecimiento económico en situación de pleno empleo se convirtió, en la segunda parte del siglo Xx, en la gran justificación para ensanchar los límites de la intervención estatal en los asuntos económicos. La idea era que una economía de libre empresa privada es inestable por esencia y que el mercado funcionando libremente no presenta un mecanismo de ajuste automático que corrija los ciclos recurrentes de auge y depresión.

Desde la aparición del New Deal en los Estados Unidos, la excusa principal para la expansión de la actividad estatal fue la necesidad de recurrir al gasto público para eliminar el desempleo. Al principio, el gasto público se justificó para "cebar la bomba"; posteriormente, se dio preferencia a la idea de que el gasto estatal no debe ni cebar la bomba ni tratar de impedir el estancamiento, sino actuar como una fuerza equilibradora. Al final, los defensores del gasto público aceptaron la presencia del fenómeno macroeconómico denominado crowding-out y justificaron el ascenso del sector público para resolver las fallas del mercado en términos de bienestar social, provisión de bienes y servicios públicos e impacto ambiental.

Pero cuando de la política monetaria se trata, para Friedman esta no debería intentar fijar los tipos de interés de forma permanente, sino solamente en periodos de tiempo muy limitados. La conclusión general es que la autoridad monetaria controla variables nominales directamente, y en principio puede utilizar ese control para mantener un tipo de cambio nominal, el nivel nominal de la renta, la cantidad de dinero, la tasa de inflación, pero no para sostener variables reales como la tasa de interés real o la tasa de desempleo.

Como la política monetaria no puede sostener esas magnitudes reales en niveles predeterminados, más bien lo que sí puede hacer es producir efectos importantes sobre esas magnitudes y lo uno no es en absoluto incompatible con lo otro. El dinero es un instrumento extraordinariamente eficiente y, sin él, no se hubiera podido conseguir el asombroso aumento en la producción y el nivel de prosperidad experimentado. El dinero lo invade todo y por ello cuando se desordena, se convierte en un desestabilizador del sistema económico. La Gran Depresión de la década de los treinta, la gran inflación en los países desarrollados en los años setenta y la hiperinflación de América Latina en los ochenta son una evidencia de ello. 
La primera y más importante lección que enseña la historia acerca de lo que puede hacer (y es una lección de la más profunda importancia) es que la política monetaria puede impedir que el dinero mismo sea una fuente importante de perturbación económica [...]. Un segundo trabajo que la política monetaria puede hacer es suministrar un fondo estable para la economía -siguiendo con la imagen de Mill mantener la máquina bien engrasada-. Cumplir la primera tarea contribuirá a ese objetivo, pero esta segunda finalidad es más amplia. Nuestro sistema económico funcionará mejor cuando los productores y consumidores, los empresarios y trabajadores, puedan proceder con plena confianza de que el nivel medio de precios se comportará de manera conocida en el futuro, preferentemente, que permanecerá altamente estable. (Friedman, 1968 , pp. 12 y 13)

Con base en la lección expuesta, Friedman defendió la conveniencia de basar la política monetaria en una regla funcional y predecible. En su opinión, "la autoridad monetaria debía guiarse mediante magnitudes controlables, y si se toma la tasa de interés o la tasa de desempleo presente como criterio inmediato de política -su comportamiento-, esto sería parecido al de una nave espacial que se hubiese fijado en una estrella equivocada" (Friedman, 1968, p. 15).

De igual forma, tratar de controlar directamente el nivel de precios es, por consiguiente, hacer de la política misma una fuente de perturbación económica a causa de las falsas paradas y arranques. Lo preferible sería adoptar un tipo de crecimiento en la oferta monetaria que produzca inflación o deflación moderada con tal de que sea firme y evite las grandes oscilaciones en la política que producen perturbaciones erráticas en la economía.

Al fijarse un punto firme y mantenerlo, defiende con vehemencia Friedman, la autoridad monetaria realizaría un importante aporte para promover la estabilidad económica. Por tanto, la regla monetaria es el mejor criterio para manejar la política al respecto, la cual debe definir el agregado monetario que se va a controlar y una norma constitucional que determine su ritmo de crecimiento.

En el estado actual de nuestro saber, me parece más conveniente expresar la norma en términos referidos al comportamiento del stock de dinero. De momento, yo preferiría una orden legislativa a la autoridad monetaria para que alcancen un determinado ritmo de crecimiento del stock monetario. Con esta finalidad mi definición del stock de dinero incluiría la moneda en existencia fuera de los bancos más todos los depósitos en los bancos comerciales. Yo especificaría que la Reserva Federal se encargara de que el stock de dinero, se elevara cada mes entre un tres y cinco por ciento anual. No importa tanto cual sea la definición de dinero que adoptemos o el ritmo de crecimiento que adoptamos, lo importante es adoptar una definición y ritmo de crecimiento concretos.

Quiero dejar bien claro que yo no considero mi propuesta como la última y la única palabra en la dirección de los asuntos monetarios, ni como una regla que haya que grabar en tablas de 
oro y guardar para la posteridad. Pero me parece que es la norma que ofrece la mayor garantía de alcanzar un grado de estabilidad monetaria razonable, a la luz de nuestros conocimientos actuales. No es exagerado afirmar que, a corto plazo, la amenaza más seria a la libertad económica a los Estados Unidos hoy día es que nos veremos forzados a adoptar controles económicos de gran importancia para poder "solucionar" los problemas en balanza de pagos. (Friedman, 2012, p. 62)

A propósito de la regla de Friedman, Hayek, a partir de su evaluación histórica en Gran Bretaña de la política monetaria en 1844, en la que el Banco de Inglaterra intentó fijar un límite a la circulación de notas bancarias, medida que fue eludida al experimentarse tres crisis de manera sucesiva, concluyó: "Creo que la propuesta de Friedman llevaría a la misma situación, porque en una situación de crisis los agentes al considerar que la demanda por liquidez puede superar el límite legal establecido, la consecuencia será la precipitación de pánicos bancarios" (AEI, 1975, p. 16). Para Hayek, un margen de discrecionalidad y elasticidad son elementos importantes para los bancos centrales.

En un sentido similar se pronunció Burns en una entrevista al señalar que la regla podría ser asociada a un monetarismo rígido, un tipo de mecanización del proceso de toma de decisiones que resultaría perjudicial. El argumento de Burns era la dificultad de establecer una tasa de crecimiento constante sobre algo que los monetaristas denominan la oferta de dinero, cuya definición debía tomar en cuenta simultáneamente aspectos cruciales como: la misma definición de dinero y de oferta de dinero. Por esta razón, la discrecionalidad no podía ser descartada y se tornaba imprescindible en las decisiones de política monetaria:

... en un mundo con una tecnología financiera en explosión, con todos los tipos de nuevas monedas o sustitutos del dinero siendo creados. La definición de dinero de los 1950s no encajaría en el entorno financiero de hoy. Usted no puede ignorar cambios en instrumentos financieros, instituciones y mercados, incluso si supone que la autoridad monetaria es realmente capaz de mantener el crecimiento de algo llamado dinero en una proporción estable. Además, eso es imposible; ningún banco central en el mundo ha sido capaz de obtener una tasa de crecimiento del dinero constante. Si vivimos en un mundo en el que la tecnología financiera fuera constante, en el que las actitudes con respecto a los saldos que las personas desean mantener en relación con sus transacciones fueran constantes, entonces podríamos funcionar con una regla que minimizara la discreción. Pero ese no es el mundo en el que vivimos. (Burns y Bartel, 1985, p. 25)

Desde 2001, y en particular desde la crisis de 2008, los principales académicos monetarios como John Taylor o Allan Meltzer han criticado a los bancos centrales por apartarse demasiado de los sistemas basados en reglas (Rogoff, 
2017, p. 256). Sin embargo, las reglas sencillas pueden rendir bien durante largos periodos pero es necesario no convertirlas en camisa de fuerza porque ante eventos críticos, como los "cisnes negros", es necesario recurrir a políticas discrecionales.

No obstante, como señala White (2012), en sus trabajos Friedman apenas aconsejó a la Fed sobre qué tan rápido debía elevarse el crecimiento en la oferta monetaria o a qué nivel debía ser establecida la tasa de interés interbancaria. Más bien, lo que ofreció Friedman fue una perspectiva general respecto a mejoras en reformas técnicas y constitucionales en el régimen de formulación de políticas, como lo muestra la tabla 1 .

Tabla 1: Mejoras en reformas técnicas y constitucionales del régimen de formulación de políticas

\begin{tabular}{|c|c|c|}
\hline & Artículos & Propuesta de Friedman \\
\hline 1 & $\begin{array}{l}\text { A program for Monetary } \\
\text { Stability (1950) y Capitalism } \\
\text { and Freedom (1962) }\end{array}$ & $\begin{array}{l}\text { Formuló la regla de política monetaria que le daría notoriedad, una } \\
\text { tasa de crecimiento mensualmete constante y lenta en el stock } \mathrm{M}_{2} \text {, a } \\
\text { una tasa gradual que genere una tasa de inflación cero en promedio } \\
\text { y a veces, aquella regla serviría para reemplazar al Federal Open } \\
\text { Market Committee (FOMC) por un robot. }\end{array}$ \\
\hline 2 & $\begin{array}{l}\text { The Optimum Quantity of } \\
\text { Money (1969) }\end{array}$ & $\begin{array}{l}\text { Elaboró un caso técnico para exponer la conveniencia teórica de una } \\
\text { defleción suave ( } 2 \% \text { anual) por lo que la tasa de interés nominal so- } \\
\text { bre los bonos de corto plazo libres de riesgo sería cero, reduciendo } \\
\text { los costos de oportunidad públicos de mantener el dinero fiduciario } \\
\text { en su costo de producción cero. Esta idea no fue promovida en sus } \\
\text { escritos populares. }\end{array}$ \\
\hline 3 & $\begin{array}{l}\text { Monetary Policy: Tactics } \\
\text { versus Strategy (1984) y } \\
\text { otros trabajos }\end{array}$ & $\begin{array}{l}\text { Pidió la congelación de los pasivos monetarios de la Fed mediante } \\
\text { una regla de crecimiento porcentual del cero porciento para el agre- } \\
\text { gado monetario } \mathrm{M}_{0} \text {. La consecuencia más importante de dicha regla } \\
\text { es que eliminaría completmente el papel de la Fed en la conducción } \\
\text { de la politica monetaria. El FoMC se enviaría a casa. }\end{array}$ \\
\hline
\end{tabular}

Fuente: adaptado de White (2012).

Como Friedman estaba convencido de que existía una relación estable a largo plazo entre la base monetaria, la inflación y el crecimiento económico, su teoría sostenía que la mejor manera de asegurar un crecimiento y una inflación estable era mantener la oferta monetaria en una senda de crecimiento estable y predecible (regla del K\%).

Aunque comprendía perfectamente que la política monetaria podía ser un instrumento potente para la estabilización macroeconómica, argumentaba que 
los bancos centrales eran propensos a las finanzas inflacionarias de tal forma que la vida sería menos azarosa si se dejara de lado y para siempre el concepto de la política monetaria activista keynesiana. Por esta razón, insistía en que la mejor manera de garantizar una política monetaria pasiva era aprobar una enmienda constitucional que fijara la tasa de expansión monetaria a perpetuidad.

Pero, curiosamente, al mismo tiempo y en los últimos años, el estrecho vínculo entre la oferta monetaria y la inflación que Friedman había subrayado comenzó a desaparecer. Recientemente, el profesor de Princenton, Steve Guidford, llamó la atención sobre el caso del dinero desaparecido (missing money) debido a una mezcla de nuevas tecnologías, liberalización financiera y desregulación. Si la enmienda constitucional de Friedman se hubiera aprobado, el mundo más bien habría conocido tasas de inflación muy erráticas. Esto es lo que explica la razón por la que los bancos centrales independientes cambiaron su forma de actuar, prestando mayor atención a las expectativas de largo plazo.

En 2010, en medio de la crisis financiera, Krugman (2012) mencionó que Blanchard, como economista en jefe del Fondo Monetario Internacional (FMI), se atrevió a publicar un documento que retaba al análisis convencional que venía haciendo dicha institución y proponía que la Reserva Federal y el Banco Central Europeo debían replantear sus metas de inflación del $2 \%$ y propender por una inflación objetivo del $4 \%$ anual.

En defensa de esta nueva meta ambos economistas argumentaron los siguientes beneficios: el primero era reducir las limitaciones que surgen por la imposibilidad de disminuir las tasas de interés por debajo de cero ya que, de acuerdo con Irving Fisher, ante las expectativas de una inflación elevada, los prestatarios se verán inducidos a tomar más préstamos y gastar más. Segundo, siguiendo de nuevo a Fisher, ante el exceso de deuda, la inflación sería un medio que permitiría reducir el valor real de dicha deuda, en especial la hipotecaria. Por último, retomando a Keynes, si los salarios poseen una rigidez nominal hacia la baja, es más fácil que los trabajadores acepten una reducción en sus ingresos reales que un recorte en sus salarios nominales.

Entre las reglas actuales, quizá la más conocida sea la regla de Taylor que propone que el banco central fije su política de tipos de interés de acuerdo con las desviaciones de la producción respecto a su nivel de pleno empleo y de la inflación con respecto a la meta. La regla de Taylor tiene muchas virtudes y 
hay consenso en que es un avance sustancial respecto al patrón oro y la regla de Friedman ${ }^{5}$ :

$$
\lambda\left(y_{t}-y_{t}^{*}\right)^{2}+(1-\lambda)\left(\pi_{t}-\pi^{*}\right)^{2}, \pi \in[0,1]
$$

donde $\left(y_{t}-y_{t}^{*}\right)$ es la brecha del producto, esto es, la diferencia entre los logaritmos del producto y el valor que este tomaría si no existieran rigideces nominales, $\pi_{t}$ es la inflación observada y $\pi^{*}$ es la inflación objetivo.

La política monetaria también se puede conducir bajo el esquema inflation targeting (inflación objetivo), según el cual el Banco Central busca anclar las expectativas de los agentes anunciando un rango de valores sobre el cual la tasa de inflación se debe encontrar al finalizar el año. Los defensores de esta regla de política monetaria consideran que el ideal es establecer una meta cuantitativa y puntual, aunque en determinadas circunstancias se puede establecer un rango estrecho con el fin de guiar las expectativas y conservar la credibilidad del Banco Central.

Hacia 1999, Colombia renunció al sistema de bandas cambiarias, y en el año 2001 la Junta Directiva del Banco de la República adoptó la estrategia de Inflación Objetivo (IO) para guiar su política monetaria. Aunque existen diferentes definiciones de IO, en general la estrategia debe anunciar de manera formal una meta de inflación y utilizar como instrumento de política su tasa de interés de intervención, con el fin de modificar la tasa de interés interbancaria e influenciar las tasas de interés de largo plazo, con las cuales los agentes toman sus decisiones de consumo e inversión.

\section{La crisis del año 2008 y la evolución de la política monetaria}

En 2002, Bernanke intervino en el homenaje que la Universidad de Chicago ofreció a Milton Friedman con motivo de su 90 cumpleaños, y en su discurso dijo al protagonista del acto: “en relación con la Gran Depresión, usted tenía

5 Además, la propuesta de la regla $\mathrm{k} \%$ fue abandonada por la adopción de la propuesta de inflación objetivo. 
razón. Nosotros -la Reserva Federal-fuimos responsables. Pero, gracias usted no volveremos a hacerlo" $(2002 \text {, p. } 11)^{6}$.

La declaración de Bernanke no fue aprobada por Krugman (2007), quien calificó el análisis de la obra de Friedman y Schwartz (1963) sobre las causas de la Gran Depresión como problemático e "intelectualmente deshonesto" ". El problema con la interpretación, según Krugman, es que el análisis debió adoptar una clara distinción entre el dinero que controla la Fed, la base monetaria (efectivo + reservas bancarias) y la oferta de dinero (efectivo + depósitos bancarios). Con esta diferenciación el análisis monetario de dicho periodo evidenciaría una trampa de la liquidez.

Schwartz y Nelson (2008a), inconformes con el veredicto de Krugman (2007), lo acusaron de descalificar severamente el legado y el análisis de Friedman sobre la política monetaria de los Estados Unidos en la década de los treinta. Según estos autores, los responsables de la Reserva Federal se opusieron a la compra de mercado abierto por su adhesión a la real bill doctrine que consideraba como especulativas e ilegítimas las compras de títulos gubernamentales de la Fed y creyeron que los bancos comerciales eran los únicos que podían otorgar préstamos orientados a propósitos productivos. Por consiguiente, la postura de la Fed era que cualquier expansión adicional de dinero era peligrosa porque estimularía la especulación.

Además, sobre el argumento de Krugman (2007) de la ocurrencia de una trampa de la liquidez durante la Gran Depresión, los autores sostienen que demostrar su evidencia requiere de ejemplos concretos que demuestren que las medidas expansionistas de la Fed en la oferta de dinero no conducen a la creación adicional de depósitos bancarios y fracasan en persuadir al público de gastar saldos monetarios adicionales. El problema, dicen los autores, es que dichos ejemplos no están disponibles.

6 En 2004, un ejemplar del Cato Journal celebró los cuarenta años transcurridos desde la publicación de Una historia monetaria de los Estados Unidos y, en uno de los artículos, Friedman (2004) fue consistente con su postura de atribuir a la Reserva Federal la responsabilidad por la contracción entre 1929-33.

7 Su ensayo, "Who was Milton Friedman?" (2007), apareció en The New York Review of Books y desató la airada réplica de Nelson y Schwartz (2007). Pero ante la limitada extensión ofrecida por este magazín literario para responder y tratar asuntos de economía técnica, en el año siguiente, la disputa se trasladó al Journal of Monetary Economics que registró la réplica más extensa de Schwartz y Nelson (2008a, 2008b) y la contrarréplica de Krugman (2008). 
Ahora, los resultados de la aplicación de las políticas monetaristas a finales de la década de los setenta en los Estados Unidos y el Reino Unido fueron cuestionables, ya que en cada caso el control sobre la oferta de dinero no los previno de experimentar recesiones severas ${ }^{8}$. En 1979, se adoptó oficialmente el monetarismo en los Estados Unidos por medio de la fijación de objetivos monetarios que fueron abandonados prontamente en 1982, cuando la tasa de desempleo llegó a dos dígitos, y hacia 1984 se abandonó oficialmente. A partir de entonces, la Fed se comprometió a efectuar una política monetaria de ajuste discrecional que Friedman siempre desaprobó.

Finalmente, el largo estancamiento experimentado por Japón fue el laboratorio propicio para probar las posturas de Friedman y Keynes acerca de la efectividad de la política monetaria en una depresión. A pesar de que el Banco Central de Japón incrementó la base monetaria, ese dinero extra no fue utilizado para gastar, sino que fue atesorado y la oferta monetaria creció muy poco, sin lograr jalonar la actividad económica de manera importante.

Cuestión diferente es si la política monetaria del periodo posterior a 2008 respondió o no a una interpretación monetarista de la crisis 9 . Muchas cosas cambiaron desde los años setenta, y como las grandes innovaciones en el sistema financiero mundial, los denominados "derivados", que según Soros (2008), se convirtieron en armas de destrucción masiva de la economía. Esto impuso a los bancos centrales no solo el objetivo de la estabilidad monetaria, sino también la regulación financiera para garantizar la estabilidad macroeconómica general.

Otro problema fundamental que evidenció la crisis de 2008, a diferencia del Gran Crack de 1929, fue la capacidad de los instrumentos de política monetaria convencional frente a una situación de tasas de interés cero que caracteriza una situación de trampa de la liquidez. Este fenómeno bien podríamos denominarlo un "cisne negro" para la teoría de Friedman, quien nunca pensó en la posibilidad

8 Según Friedman, la política monetaria de Volcker no puede caracterizarse como monetarista ya que la tasa de crecimiento del stock monetario mantuvo una alta volatilidad (Friedman, 1982). 9 "El Sistema de la Reserva Federal, nacido del casi olvidado Pánico de 1907, fracasó en la década de 1930 cuando hubo de afrontar su primera gran prueba. Sus dirigentes y los de los bancos centrales de medio mundo se quedaron de brazos cruzados ante la ruinosa deflación y el colapso financiero. El resultado fue la Gran Depresión, las colas para recibir las ayudas sociales, un $25 \%$ de desempleo en Estados Unidos y el auge de los fascismos. Setenta y cinco años después, la Reserva Federal -la institución a cuyo estudio y servicio he dedicado los mejores años de mi vida- se enfrentó a desafíos similares en la crisis de 2007-2009 y en los años posteriores. Esta vez actuamos" (Bernanke, 2016, p. 9). 
de una expansión cuantitativa al estilo de la realizada por la Reserva Federal bajo el liderazgo de Bernanke.

Desde la crisis financiera de 2008, la mayoría de los bancos centrales de los países avanzados, incluyendo la Reserva Federal de los Estados Unidos, se han embarcado en una agresiva expansión cuantitativa de la moneda, con el objetivo de ayudar a la recuperación económica sin llevar a la economía a una alta inflación. Con todo, los bancos centrales estarían de acuerdo en que la expansión cuantitativa es una política transitoria y no un sustituto general para las políticas convencionales de tipos de interés.

Otra forma de analizar el tema es retomar la famosa regla del K \% de Friedman para el crecimiento de la base monetaria que suponía que su incremento afectaría de manera proporcional otros agregados monetarios y presionaría los precios al alza. Por el contrario, el esfuerzo cuantitativo lo que produjo fue un incremento en las reservas bancarias que se limitaron a permanecer en el banco central y nunca llegaron a la economía,

... no hay aumento en la demanda agregada y el canal por el que la expansión monetaria impulsa los precios al alza está cerrado. Esta es la razón por la cual la masiva expansión cuantitativa no ha llevado a la correspondiente inflación que de paso se necesitaba para acelerar la recuperación de la economía. (Rogoff, 2017,p. 187)

Si la política monetaria es demasiado agresiva en el límite cero y las expectativas de inflación comienzan a crecer, pronto lo harán también los tipos de interés. De hecho, es posible que el principal problema de la expansión cuantitativa, tal como se ha practicado en los últimos años, haya sido el accionar cauteloso de los bancos centrales. Como dijo el presidente del Banco Central Europeo Mario Dragui, "no han hecho lo que sea necesario".

En suma, es probable que la expansión cuantitativa sea un instrumento más débil que la política monetaria convencional y la regla del K\% de Friedman. Ahora bien, si el banco central no puede reducir el tipo de interés nominal en el límite cero manipulando las expectativas de inflación, mediante los preanuncios monetarios, aprovechando la credibilidad que los propios bancos centrales han logrado en los últimos años, existe otra alternativa. La teoría que hemos revisado sugiere que, aunque es importante el recurso a la expansión cuantitativa y los preanuncios monetarios, el instrumento más potente serían los tipos de interés reales negativos, producto de una política monetaria expansiva convencional pero radical. 
Rogoff formuló una pregunta que Friedman no consideró: ¿ha llegado el momento de que los países avanzados empiecen a eliminar gradualmente el dinero en efectivo?, su respuesta es afirmativa

... por dos razones: en primer lugar, porque probablemente tendría un impacto significativo en desincentivar la evasión fiscal y el delito, y en segundo lugar, se trata de una medida simple y elegante para que los bancos centrales apliquen políticas de tipo de interés negativo sin restricciones si chocan contra el límite inferior cero. (2017, p. 15)

La principal motivación de los bancos para repensar el papel del efectivo es que se ha convertido en un gran impedimento para el funcionamiento fluido del sistema financiero global. El límite cero ha paralizado la política monetaria en los países desarrollados durante la crisis de 2008. Si fuera posible una política de tipo de interés negativo los bancos centrales nunca se quedarían sin municiones.

La idea de que los tipos de interés negativos podrían ser en ocasiones una buena medida, no es nueva. Durante la Gran Depresión los economistas de la talla de Fisher y Keynes alcanzaron un notable consenso respecto a esta idea, pero no encontraron una solución práctica y realizable (Rogoff, 2017, p. 19).

Al final del siglo Xx y en lo que va corrido del siglo XXI, la inflación ha sido demasiado baja, a tal punto que han ocurrido más bien varios episodios de deflación. En estas circunstancias, los inflexibles regímenes de "inflación objetivo" no son buenos para manejar esta situación, en especial cuando los tipos de interés nominal tienden hacia el límite cero.

Siguiendo con Rogoff (2017, pp. 165-167), el límite cero se ha convertido en un problema por tres razones: la primera y principal, es que la inflación se ha desmoronado y con ella sus expectativas; la segunda, es que la volatilidad económica ha resultado mucho mayor de lo que la mayoría de economistas habían imaginado; $y$, la tercera, porque la tasa de interés nominal cero ha resultado tan problemática que las tasas de interés real han descendido por debajo de los niveles adecuados.

Incluso, más complicado ha resultado para los economistas encontrar una explicación para el lento crecimiento global luego de la crisis financiera. Summers (2015), que retomó la vieja teoría del estancamiento secular proferida por Alvin Hansen, sostiene que la causa del declive secular de la demanda agregada se produce cuando el sector privado no puede por sí solo generar el pleno empleo, ante lo cual la política macroeconómica es clave para la recuperación; en cambio, Gordon (2016) piensa que la explicación está en la caída aguda de la productividad total de factores por la tasa decreciente de invenciones valiosas 
y, finalmente, Rogoff (2017) expone la hipótesis de que la economía global está pasando por un superciclo de deuda que comenzó en los Estados Unidos y se ha trasladado a China. Las hipótesis señaladas son atractivas pero la verdad es que no se ha desarrollado evidencia empírica suficiente para zanjar la discusión.

Pero en lo que sí parece existir consenso es que la política monetaria normal se ha vuelto inefectiva en la lucha contra la recesión con la circunstancia especial de tasas de interés nominales cero. Esta situación, que para los keynesianos ortodoxos implica el resurgimiento de la trampa de la liquidez, fue reconocida por Bernanke (2016), quien sostuvo que con ingenio se podía sortear la situación con herramientas no convencionales, como la "expansión cuantitativa $\left(Q_{1}, Q_{2}\right)$ ") y la "política de tipos de interés en la sombra".

A juicio de Bernanke (2016), la manera de abordar la crisis de 2007-2009 es entenderla como heredera de los pánicos financieros del siglo XIX y comienzos del XX. La severidad del pánico mismo fue la causante de los grandes costos financieros y económicos de la crisis, pero con unas recetas que no permitían contenerla.

Este enfoque de Bernanke contó siempre con la resistencia de los halcones ortodoxos que, inspirados en Friedman, reivindicaban el peligro de la inflación. Para los miembros del Federal Open Market Committee (FOMC) no era claro cuándo darle fin a la política monetaria flexible, ya que los temores de los halcones se inclinaban por los efectos inflacionarios y por la toma de riesgos excesivos en los mercados financieros. Por el contrario, Bernanke se opuso al endurecimiento de la política monetaria ya que, en su experiencia, dos "episodios históricos" le daban la razón.

El primero fue durante el gobierno de Franklin Roosevelt con la recesión de 1937-1938 que terminó en una depresión por el endurecimiento de la política monetaria y fiscal en un escenario con alto desempleo. En efecto, la elevación de los impuestos, junto con la decisión de la Fed de reducir la masa monetaria, causó un retroceso en la recuperación económica del país. El segundo, corresponde a la experiencia reciente del Banco de Japón que de manera precipitada endureció su política monetaria en 2000 y en 2007 con el resultado de que en ambas ocasiones tuvo que abandonar sus pretensiones de mantener los tipos de interés cero. De esta manera, lo que se esperaba en el FOMC era el diseño de una estrategia funcional que señalara el momento adecuado para el endurecimiento de la política económica.

En realidad, para Bernanke la situación en 2009 lo llevaba a admitir que los tipos de interés podrían mantenerse cercanos a cero por un buen tiempo. 
Igualmente, esta posibilidad lo condujo a reflexionar que ante dicha situación la política monetaria no perdía su capacidad para operar sobre la economía, por lo que había llegado el momento de poner en práctica sus ideas, que implicaban el fin de las medidas de austeridad económica.

El instrumento relevante, como se mencionó, fue la compra masiva de valores al sistema bancario para evitar su bancarrota y sus efectos devastadores en la economía. Tanto fue así que dicha herramienta adoptó el nombre de expansión cuantitativa (QE, por las siglas en inglés), la compra de activos a gran escala comenzó a utilizarse por medio del rescate a Fannie y Freddie en diciembre de 2008 y, posteriormente, la compra de valores del Tesoro.

Hacia marzo de 2009, en la reunión del FOMC reinaba el pesimismo; el temor estaba fundamentado en la fragilidad del sistema financiero, el descenso del Dow Jones, el crecimiento en el desempleo y la declinación en el comercio internacional que reforzaban las expectativas sombrías. De ahí que emergiera la propuesta de comprar títulos respaldados por hipotecas o valores del Tesoro, las cuales tenían efectos diferentes, en el primer caso sus efectos se sentirían principalmente en el mercado hipotecario y, en el segundo, el efecto sería más general.

En palabras de Bernanke, la decisión tomada por el comité fue adoptar ambas opciones, de esta manera, emprendieron una política activa de compra de valores que se transformó en el programa $\mathrm{QE}_{\mathrm{I}}$, el cual fue un paquete integral que redujo los tipos de interés de los fondos federales que incidieron en los tipos de interés de corto plazo y que se transmitieron a los de largo plazo.

Lo anterior fue el preludio de una era de activismo en la política monetaria que propició la recuperación económica corroborada por el crecimiento de 1,3 y $3,9 \%$ experimentado en el tercer y cuarto trimestres respectivamente. Esta política monetaria expansionista sería imitada por otros bancos centrales como el Banco de Inglaterra y el Banco de Japón que comenzaron a impulsar la compra de bonos del Estado, a diferencia del Banco Central Europeo cuya compra de activos fue más restringida y se enfocó en liberar a los bancos de préstamos a largo plazo.

Krugman (2012) causó revuelo con un modelo neokeynesiano que promovía la idea de que después de años de lucha exitosa contra la inflación, el nuevo problema de credibilidad para los bancos centrales era convencer a la sociedad de que estaban preparados para buscar una inflación más alta, cuando la situación lo exigiera. 
De igual manera, era importante reorganizar el sistema financiero. Debido a ello, se diseñaron diversos planes de reforma financiera cuyas lecciones servirían de soporte para transformar "la anticuada y balcanizada estructura reguladora financiera de Estados Unidos" (Bernanke, 2016, p. 483). No obstante, un tema crucial que surgió tras el derrumbe de Bear Stearns y Lehman fue establecer cómo el sistema financiero podría mantenerse en pie, luego de demoler una entidad financiera grande y compleja.

Como consecuencia, se llegó al acuerdo de Basilea III que propuso como objetivo esencial incrementar el capital, principalmente de aquellas entidades importantes para el sistema financiero con transacciones que se interconectaban internacionalmente. El acuerdo se hizo público en diciembre de 2010 y consistió en incrementar la exigencia del capital en general acompañado de un colchón extra para efectos contracíclicos y así garantizar que los bancos utilicen dicho capital en épocas de bonanza, asuman las pérdidas y mantengan los préstamos en las épocas de crisis. Al año siguiente, el Comité de Basilea añadió la exigencia de que las entidades financieras consideradas importantes para el sistema debían acumular más capital que las demás.

Además, Basilea III exigió un índice de apalancamiento mínimo, al margen de los requisitos basados en el riesgo, entendido como la proporción entre el capital total del banco y sus activos totales, y amplió la exigencia a todos los bancos activos internacionalmente, incluida la Fed. Posteriormente, los reguladores en los Estados Unidos elevarían el índice de apalancamiento para sus bancos por encima del mínimo fijado en Basilea (Bernanke, 2016, p. 504).

Como se puede ver, la política macroeconómica combinaba: una política monetaria expansiva por medio de un programa de préstamos a los bancos y la compra de títulos en general, una política fiscal acomodaticia y una regulación financiera novedosa mediante la aplicación de pruebas de resistencia al sistema bancario.

\section{Anexo}

Gráficamente, la curva de Phillips refleja la distinción entre dichos salarios, si en el eje vertical plasmamos el cambio en los salarios nominales menos la tasa esperada en los precios, como muestra la figura 1, en la que la tasa de cambio en los precios anticipada está representada por $\left(\frac{1}{P} \frac{d P}{d t}\right)$ y es restada a la tasa de 
cambio de los salarios nominales $\left(\frac{1}{S} \frac{d S}{d t}\right)$, gráfica que se asemeja a la versión de Fisher.

Figura 1. Tasa de cambio en salarios-desempleo

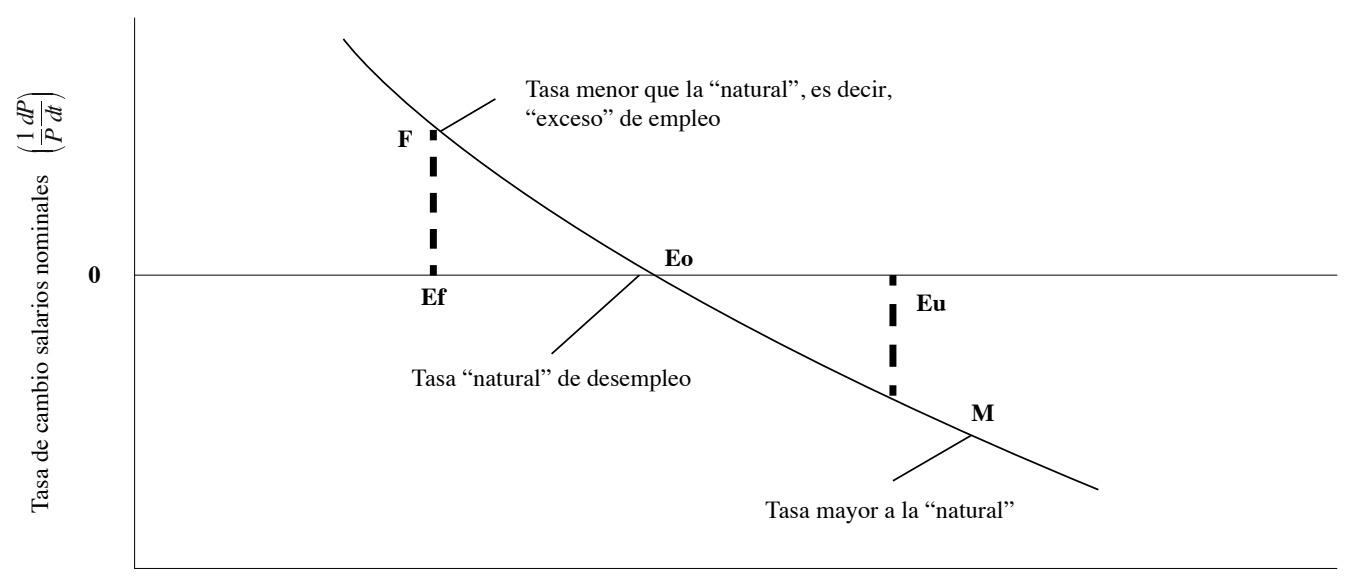

Desempleo, E

Fuente: Friedman (1992).

El análisis de Friedman toma como punto de partida el punto de equilibrio $E_{\mathrm{o}}$, con estabilidad en precios y salarios. Ahora, supongamos una política monetaria expansiva que incrementa la demanda agregada nominal y, por tanto, causa una elevación en precios y salarios a un ritmo anual del $2 \%$. La manera como los agentes empresarios y trabajadores interpretan esta situación es la siguiente: desde el inicio los trabajadores toman esta información como un incremento en su salario real ya que suponen que los precios se mantendrán constantes y, por esta razón, están dispuestos a elevar su oferta de trabajo con el resultado de aumentar el empleo a costa de un menor desempleo.

Los empresarios pronostican que el aumento en el nivel de precios coincide con el efectuado por los trabajadores. Pero los empresarios están más preocupados por el precio de sus productos sobre los que poseen mejor información. Por ello, desde el inicio, su interpretación del aumento de la demanda y del precio de su producto se traducirá en un alza de su precio relativo, por lo que el salario real que paga se ha reducido en términos comparativos al valor de los bienes producidos que incentivará a los empresarios a contratar más trabajadores. Por tanto, en la gráfica resultado se observará en un desplazamiento del 
punto $E_{\mathrm{o}}$ al punto $F$, donde el desempleo es inferior al de equilibrio a una tasa de crecimiento de los salarios nominales del $2 \%$.

No obstante, esta nueva posición en el punto $\mathrm{F}$ no puede mantenerse permanentemente, empresarios y trabajadores terminan percatándose de que el incremento en precios es general y finalizan ajustando al alza su cálculo de la inflación prevista, por lo que la tasa de crecimiento de los salarios reales previstos se ajusta hacia la baja y genera un deslizamiento sobre la curva: del punto $\mathrm{F}$ se traslada hacia el punto de equilibrio inicial $E_{\mathrm{o}}$.

Figura 2. Tasa de cambio en salarios-desempleo

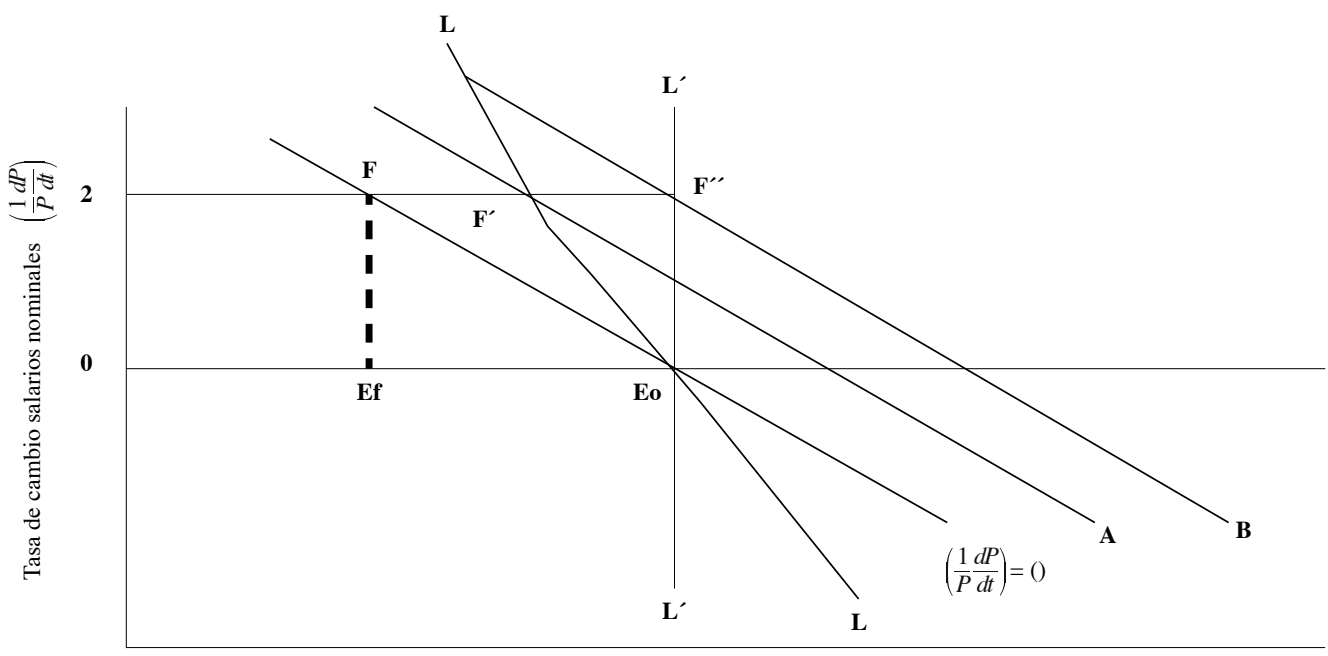

Desempleo, E

Fuente: Friedman (1992).

En la figura 2, el eje vertical es la tasa de cambio de los salarios nominales y aparecen diferentes curvas, una por cada tasa anticipada de salarios. Así, podemos escribir algebraicamente la relación que establece la curva de Phillips de la siguiente manera:

$$
\frac{1}{S} \frac{d S}{d t}=\left(\frac{1}{P} \frac{d P}{d t}\right)^{*}=f(M)
$$

Siendo M el desempleo, dicha ecuación podemos reescribirla de la siguiente forma: 


$$
\frac{1}{S} \frac{d S}{d t}=f\left[M,\left(\frac{1}{P} \frac{d P}{d t}\right)^{*}\right]
$$

Ahora, si nuestro análisis comenzara con una situación de equilibrio en $E_{\mathrm{o}}$, si ante un cambio la economía se desplaza al punto $F$, donde los salarios están creciendo al $2 \%$ anual y el desempleo se reduce por debajo de la tasa natural, se producirá un ajuste de las expectativas de inflación por parte de los agentes y, por consiguiente, la curva de Phillips de corto plazo se desplazará hacia arriba hasta el punto en el cual la tasa esperada de inflación iguale a la tasa obtenida en el presente.

Ahora, lo importante es determinar en la figura si la curva de Phillips de corto plazo que se desplazó es la $A$ ya que tendríamos que la curva de Phillips de largo plazo sería LL, de tal modo que al tener una tasa de inflación esperada del $2 \%$ el desempleo podría seguir descendiendo. Pero si la curva es la $B$, la curva de Phillips de largo plazo sería vertical L'L', lo cual implica que a una tasa de inflación anticipada del $2 \%$ le corresponde un nivel de desempleo que va a ser el mismo si la tasa anticipada es igual al $0 \%$. Esto lo podemos observar a partir de la ecuación (5) que se reformula luego de realizar una extensa verificación de estudios estadísticos, de la siguiente manera:

$$
\frac{1}{P} \frac{d P}{d t}=a+b\left(\frac{1}{P} \frac{d P}{d t}\right)^{*}+f(M)
$$

De esta ecuación, si suponemos que b es igual a uno, por consiguiente, si la inflación actual es la misma que la inflación anticipada, es decir, cuando estamos en la curva de Phillips vertical de largo plazo, tenemos:

$$
f(M)=-a
$$

En (7), el valor de $M$ corresponde a la tasa natural de desempleo. De este modo, valores diferentes a $M$ son equivalentes a posiciones de equilibrio de corto plazo o un componente aleatorio de la tasa natural. Esto conduce a que, en el proceso de cálculo empleado, teniendo en el lado izquierdo $\left(\frac{1}{P}\right)\left(\frac{d P}{d t}\right)$ se traten 
como variables exógenas las tasa de observadas como si estas pudieran persistir de manera indefinida, por lo cual no habría forma de la obtener la ecuación (7). De esa manera, suponer que el desempleo puede tomar diferentes valores implica admitir aquello que está cuestionado por la hipótesis aceleracionista. Estadísticamente significa que para aplicar el método en cuestión se requiere poner un $M$ al lado izquierdo o una función de la misma $\left(\frac{1}{P}\right)\left(\frac{d P}{d t}\right)$.

\section{Referencias}

AEI (1975). A Discussion with Friedrich von Hayek, Washington, AEI.

Bernanke, B. (2002). On Milton Friedman’s ninetieth birthday. En Remarks at the Conference to Honor Milton Friedman. Chicago: University of Chicago.

Bernanke, B. (2016). El valor de actuar. Memoria de una crisis y sus secuelas. Bogotá: Crítica.

Blanco, A. (1999). Macroeconomía y desarrollo económico. Bogotá: Universidad Externado de Colombia.

Brunner, K. (1968a). Introduction. En The Supply and Control of Money in the United States, by Lauchlin Currie. New York: Russell \& Russell.

Brunner, K. (1968b). The role of money and monetary policy, Review (June), Federal Reserve Bank of St. Louis.

Burns, A. y Bartel, R. (1985). An economist's perspective over 60 years. Challenge, 27(6), 17-25.

Currie, L. (1931a). Bank Assets and Banking Theory (Ph.D. dissertation). Harvard University.

Currie, L. (1931b). Review of Federal Reserve Policy, 1921-1930, by Harold L. Reed. American Economic Review, 21(1), 162-64.

Currie, L. (1934a). The failure of monetary policy to prevent the depression of 192932. Journal of Political Economy 42(2), 145-77. 
Currie, L. (1934b). The Supply and Control of Money in the United States. New York: Russell \& Russell, 1968.

Friedman, M. (1956). The Quantity Theory of Money - A Restatement. En Studies in the Quantity Theory of Money (pp. 3-21). Chicago: University of Chicago Press.

Friedman, M. (1957). Una teoría de la función consumo. Madrid: Alianza.

Friedman, M. (1968). The role of monetary policy. American Economic Review, 58(1), $1-17$.

Friedman, M. (1982). Defining monetarism. Newsweek, July 12. Recuperado de: https://miltonfriedman.hoover.org/friedman_images/Collections/2016c21/ NW_07_12_1982.pdf

Friedman, M. (1992). La economía monetarista. Barcelona: Gedisa.

Friedman, M. (1994). Milton Friedman. En B. Snowdon, H. Vane y P. Wynarczyk (eds.), A Modern Guide to Macroeconomics. An Introduction to Competing Schools of Thought. Cambridge: Edward Elgar.

Friedman, M. (2004). Reflections on a monetary history. Cato Journal, 23(3), 349-351.

Friedman, M. (2012 [1962]). Capitalismo y libertad. Ensayos de política monetaria. Madrid: Síntesis.

Friedman, M. y Friedman, R. (1984). La tiranía del status quo. Barcelona: Ariel.

Friedman, M. y Friedman, R. (1998 [1980]). Libertad de elegir. Barcelona: Orbis.

Friedman, M. y Schwartz, A. (1963). A Monetary History of the United States, 18671960. Princeton NJ: Princeton University Press.

Gordon, R. (1974). Milton Friedman's Monetary Framework. A Debate with His Critics. Chicago and London: The Chicago University Press.

Gordon, R. (2016). The rise and fall of american growth. Princeton, NJ: Princeton University Press. 
Humphrey, T. M. (1971). Role of Non-Chicago Economists in the Evolution of the Quantity Theory in America, 1930-1950. Southern Economic Journal, 38(1), 12-18.

Ip, G. y Whitehouse, M. (2006). How Milton Friedman Changed Economics, Policy and Markets. Wall Street Journal, November 17. Recuperado de http://www. columbia.edu/ esp2/WsJ\%20Whitehouse\%20Article.pdf

Kaldor, N. (1987). La economía keynesiana cincuenta años después. Investigación Económica, 46(181), 13-66.

Keynes, J. (1997 [1936] ). The General Theory of Employment, Interest and Money. London: Prometheus Books.

Krugman, P. (2007a). Response to Nelson and Schwartz. Journal of Monetary Economics, 55(4), 857-860.

Krugman, P. (2007b). Who was Milton Friedman? The New York Review of Books 54, 27-30.

Krugman, P. (2012). Acabemos ya con la crisis. Barcelona: Crítica.

Laidler, D. (1993). Hawtrey, Harvard, and the Origins of the Chicago Tradition. Journal of Political Economy, 101(6), 1068-1103.

Mankiw, G. y Ries, R. (2018). Friedman's Presidential Address in the Evolution of Macroeconomic Thought. Journal of Economics Perspectives, 32(1), 81-96.

Mehra, Y. P. (1978). Is money exogenous in money- demand equations. The Journal of Political Economy, 86(2), 211-228.

Modigliani, F. y Brumberg, R. (1954). Utility analysis and the consumption function: An interpretation of cross section data. En K. Kurihara (ed.). Post Keynesian Economics (pp. 388-436). New Brunswick, NJ: Rutgers University Press.

Mundell, R. (2003). A reconsideration of the Twentieth Century. En T. Persson (ed.), Nobel lectures, Economics 1996-2000. Singapore: World Scientific Publishing Co.

Nelson, E. (2007). Milton Friedman and U.S. Monetary History: 1961-2006. Federal Reserve Bank of St. Louis Review, 89(3), 153-82. Recuperado de https://doi. org/10.20955/r.89.153-182 
Nobelprize.org (2017). Simon Kuznets-Biographical. Nobel Media AB 2014. Recuperado de http://www.nobelprize.org/nobel_prizes/economic-sciences/laureates/1971/ kuznets-bio.html

NobelPrize.org (2018). Milton Friedman-Facts-NobelPrize.org. Recuperado de https:// www.nobelprize.org/prizes/economics/1976/friedman/facts/

Patinkin, D. (1973). On the monetary economics of chicagoans and non-chicagoans: Comment. Southern Economic Journal, 39(3), 454-59.

Rogoff, K. (2017). Reduzcamos el papel moneda. Barcelona: Deusto.

Sandilands, R. (1990). The Life and Political Economy of Lauchlin Currie: New Dealer, Presidential Adviser, and Development Economist. Durham, N.C.: Duke University Press.

Schwartz, A. y Nelson, E. (2007). In response to: Who was Milton Friedman? The New York Review of Books, 54, 48-50.

Schwartz, A. y Nelson, E. (2008a). The impact of Milton Friedman on modern monetary economics: Setting the record straight on Paul Krugman's "Who was Milton Friedman”. Journal of Monetary Economics, 55(4), 835-856.

Schwartz, A. y Nelson, E. (2008b). Rejoinder to Paul Krugman. Journal of Monetary Economics, 55(4), 861-862.

Sims, C. (1972). Money, Income and Causality. American Economic Review, 62(2), 540-552.

Sims, C. (1980). Macroeconomics and reality. Econometrica, (48), 1-48.

Sims, C. (1989). Models and Theirs Uses. American Journal of Agricultural Economics, $71,489-494$.

Sims, C. (2011). Statistical Modeling of Monetary Policy and Its Effects. Nobel Prize. Princenton, NJ: Princenton University Press. Recuperado de http://www.nobelprize. org/nobel_prizes/economic-sciences/laureates/2011/sims-lecture.html

Soros, G. (2008). El nuevo paradigma de los mercados financieros. Para entender la crisis económica actual. Madrid: Taurus. 
Steindl, F. (1991). The monetary economics of Lauchlin Currie. Journal of Monetary Economics, 27(3), 445-61.

Summers, L. (19 de noviembre de 2006). The Great Liberator. The New York Times. Recuperado de https://www.nytimes.com/2006/11/19/opinion/19summers.html

Summers, L. (2015). Demand side secular stagnation. American Economic Review, $105(5), 60-65$.

Tobin, J. (1981). The monetarist counter-revolution today - an appraisal. The Economic Journal, 91(361), 29-42.

White, L. (2012). The Clash of Economic Ideas. New York: Cambridge University Press. 